Article

\title{
Sulfoxaflor Residues in Pollen and Nectar of Cotton Applied through Drip Irrigation and Their Potential Exposure to Apis mellifera L.
}

\author{
Hui Jiang ${ }^{1,2}$, Jianjun Chen ${ }^{3}$, Chen Zhao ${ }^{1,2} \oplus$, Yongqing Tian ${ }^{1,2}$, Zhixiang Zhang ${ }^{1,2, *}$ \\ and Hanhong $\mathrm{Xu}$ 1,2,* \\ 1 State Key Laboratory for Conservation and Utilization of Subtropical Agro-Bioresources, \\ South China Agricultural University, Guangzhou 510642, China; jianghuizukai@stu.scau.edu.cn (H.J.); \\ zhaoc@scau.edu.cn (C.Z.); tyq2006@scau.edu.cn (Y.T.) \\ 2 Key Laboratory of Natural Pesticide and Chemical Biology, South China Agricultural University, \\ Guangzhou 510642, China \\ 3 Department of Environmental Horticulture and Mid-Florida Research and Education Center, \\ Institute of Food and Agricultural Sciences, University of Florida, Apopka, FL 32703, USA; jjchen@ufl.edu \\ * Correspondence: zdsys@scau.edu.cn (Z.Z.); hhxu@scau.edu.cn (H.X.)
}

Received: 29 December 2019; Accepted: 6 February 2020; Published: 10 February 2020

check for updates

\begin{abstract}
Systemic insecticides have been applied through drip irrigation for controlling crop pests, but few studies have addressed potential negative effects of the application on non-target organisms. In this study, the safety of sulfoxaflor applied at 450 or $700 \mathrm{~g}$ a.i. ha ${ }^{-1}$ through drip irrigation at different times before flowering or during flowering to honey bee (Apis mellifera L.) was studied in 2016-2017 in a cotton production field in Xinjiang, China. Results showed that sulfoxaflor residues in pollen and nectar of cotton treated with sulfoxaflor at $450 \mathrm{~g}$ a.i. ha ${ }^{-1}$ before and during flowering through drip irrigation were either undetectable or no more than $17 \mu \mathrm{g} \cdot \mathrm{kg}^{-1}$. Application of sulfoxaflor at $700 \mathrm{~g}$ a.i. $\mathrm{ha}^{-1}$ before flowering resulted in $\leq 14.2 \mu \mathrm{g} \cdot \mathrm{kg}^{-1}$ of sulfoxaflor in pollen and $<0.68 \mu \mathrm{g} \cdot \mathrm{kg}^{-1}$ in nectar. Sulfoxaflor applied at this higher rate during flowering had the highest residue, up to $39.2 \mu \mathrm{g} \cdot \mathrm{kg}^{-1}$ in pollen and $13.8 \mu \mathrm{g} \cdot \mathrm{kg}^{-1}$ in nectar. Risk assessments by contact exposure and dietary exposure showed that drip application of sulfoxaflor at the two rates before or during flowering posed little risk to honey bees. Thus, drip application of sulfoxaflor could represent an environmentally benign method for controlling cotton aphid.
\end{abstract}

Keywords: Aphis gossypii; Apis mellifera; drip irrigation; sulfoxaflor; residue level

\section{Introduction}

Drip application of chemicals or chemigation is a method of delivering insecticides to plant root zones for the control of crop pests [1-4]. Chemigation has numerous advantages, including uniform distribution of insecticides and reduction in application times, manpower, and cost [3,5-7]. Increasing reports have shown that insecticides applied via drip irrigation exhibited higher efficacy against crop pests than the conventional foliar spray method [2-4,6,8-10].

Xinjiang is the world's most important cotton-producing region, accounting for $10 \%$ of the annual global cotton lint production and about $50 \%$ of the cotton yield in China [11]. Cotton production in Xinjiang is primarily irrigated through a drip system $[12,13]$. Cotton farming has served as an engine of economic growth and provided income to millions of farmers in cotton production regions [14]. However, cotton aphid (Aphis gossypii Glover) is a major recurrent pest in cotton plants and a notorious problem significantly affecting cotton lint yield and quality. 
Foliar spraying of neonicotinoids, such as imidacloprid, thiamethoxam, and clothianidin, is a common method used for the control of aphid in Xinjiang. However, increasing negative impacts on important pollinators like bees had led to the ban of pesticide applications in open fields. Bees are the most important group of pollinators worldwide, $35 \%$ of the world food crop production depends on pollinators $[15,16]$. Sulfoxaflor is a novel sulfoximine insecticide, which exhibits high degree efficacy against a wide range of sap-feeding insect pests, including many that are resistant to neonicotinoids [17-19]. A recent report showed that drip irrigation of sulfoxaflor was more effective in the control of cotton aphid than conventional foliar spray [9]. Although sulfoxaflor and neonicotinoids are chemically distinct, they share a common biological mode of action [20]. This raises major concerns about the potential effects of sulfoxaflor on non-target species, particularly on honey bees. Some reports showed that sulfoxaflor had high toxicity to honey bees, and its LD $_{50}$ (median lethal dose) was lower than $0.6 \mu \mathrm{g}$ a.i./bee [21-23]. According to the experimental guideline for environmental safety evaluation of chemical pesticides, a pesticide is classified highly toxic to honeybees if the $\operatorname{LD}_{50}$ is $<2 \mu \mathrm{g}$ a.i./bee [24]. A recent study reported that sulfoxaflor applied via foliar spray had severe sub-lethal effects on bumblebee (Bombus terrestris L.) colonies [23]. However, no one has reported the residue level of sulfoxaflor applied via drip irrigation in cotton flowers and its risk to honey bee (Apis mellifera L.) in an open field. Therefore, there is an urgent need to pre-emptively evaluate the potential effects of sulfoxaflor applied through drip irrigation on A. mellifera in cotton production field; such effects are rarely detected by standard ecotoxicological assessments but can have major impacts at larger ecological scales [25-27].

The present study was intended to determine the residue levels of sulfoxaflor applied through drip irrigation in cotton flowers in a cotton production field in Xinjiang. Sulfoxaflor at two rates were applied via drip irrigation at different times before and during flowering, and sulfoxaflor residues in pollen and nectar were tested. Additionally, the potential risk of the residue to honey bee was evaluated. Our results showed that the drip application of sulfoxaflor at the two rates posed little risk to honey bee during cotton production in Xinjiang.

\section{Materials and Methods}

\subsection{Chemicals and Reagents}

Sulfoxaflor of certified reference standard (98\% purity, CAS number 946578-00-3) was bought from Shanghai Mingbo Biotechnology Co., Ltd (Shanghai, China). Sulfoxaflor 50\% water dispersing granule (WDG) was provided by Dow AgroSciences (Zionsville, IN, USA). HPLC-grade acetonitrile, AR-grade acetonitrile, and sodium chloride were purchased from Tianjin Fuchen Chemical Reagent Factory (Tianjin, China). PSA and $\mathrm{C}_{18}$ were purchased from Sigma Aldrich (Steinheim, Germany). Ultrapure water was obtained using Millipore Milli-RO plus and Milli-Q systems (Bedford, MA, USA).

\subsection{Experiment Design}

The field experiments were conducted at Bole County, Xinjiang Uygur Autonomous Region, northwest China $\left(44^{\circ} 20^{\prime}-45^{\circ} 23^{\prime} \mathrm{N}\right.$ and $\left.79^{\circ} 53^{\prime}-83^{\circ} 53^{\prime} \mathrm{E}\right)$ in 2016 and 2017, respectively. On 5 April 2016 and 24 April 2017, cotton seed (Xinliuzao-42) was sown in a field installed with a drip irrigation system under the film. The experimental field site was similar to our previously reported site [9].

Experiments were initiated on 3 June 2016 and 10 June 2017, and the application rate of sulfoxaflor was $450 \mathrm{~g}$ a.i. $\mathrm{ha}^{-1}$ and $700 \mathrm{~g}$ a.i. ha ${ }^{-1}$. The application rates were chosen based on previous test results of sulfoxaflor (drip irrigation: sulfoxaflor, $700 \mathrm{~g}$ a.i. ha ${ }^{-1}$ ) in a cotton field in Xinjiang [9]. The detailed calendar of sulfoxaflor treatments is presented Table 1. In both years, sulfoxaflor was applied one time during the entire experiment. Four application times with $450 \mathrm{~g}$ a.i. ha ${ }^{-1}$ or $700 \mathrm{~g}$ a.i. ha ${ }^{-1}$, plus controls resulted in a total of 12 treatments. The experiments were arranged as a completely randomized block design with 3 replicates. Thus, a total of 36 plots were prepared. Each block was $2400 \mathrm{~m}^{2}$ encompassing 12 plots, $200 \mathrm{~m}^{2}$ each, which was separated by a $4 \mathrm{~m}$ buffer zone. Each plot had 
3200 to 3500 plants. Drip applications of sulfoxaflor at $450 \mathrm{~g}$ a.i. $\mathrm{ha}^{-1}$ or $700 \mathrm{~g}$ a.i. ha ${ }^{-1}$ following the days indicated in Table 1 based on the procedures previously described [9]. Drip controls were the same irrigation regime without any chemicals. For application during flowering, flowers were covered by wax-coated paper bags to prevent pollinator visits.

Table 1. The calendar for conducting field experiments in Xinjiang, China in 2016 and 2017.

\begin{tabular}{|c|c|}
\hline Date & Activity \\
\hline 4 April 2016 & Sowing seeds \\
\hline 3 June 2016 & Sulfoxaflor applied at $450 \mathrm{~g}$ a.i. $\mathrm{ha}^{-1}$ or $700 \mathrm{~g}$ a.i. ha $\mathrm{ha}^{-1}$ via drip irrigation 30 days before cotton flowering \\
\hline 13 June 2016 & Sulfoxaflor applied at $450 \mathrm{~g}$ a.i. $\mathrm{ha}^{-1}$ or $700 \mathrm{~g}$ a.i. ha $\mathrm{ha}^{-1}$ via drip irrigation 20 days before cotton flowering \\
\hline 13 June 2016 & Sulfoxaflor applied at $450 \mathrm{~g}$ a.i. $\mathrm{ha}^{-1}$ or $700 \mathrm{~g}$ a.i. ha $\mathrm{ha}^{-1}$ via drip irrigation 10 days before cotton flowering \\
\hline 7 July 2016 & Sulfoxaflor applied at $450 \mathrm{~g}$ a.i. $\mathrm{ha}^{-1}$ or $700 \mathrm{~g}$ a.i. $\mathrm{ha}^{-1}$ via drip irrigation during cotton flowering \\
\hline 24 April 2017 & Sowing seeds \\
\hline 10 June 2017 & Sulfoxaflor applied at $450 \mathrm{~g}$ a.i. $\mathrm{ha}^{-1}$ or $700 \mathrm{~g}$ a.i. $\mathrm{ha}^{-1}$ via drip irrigation 30 days before cotton flowering \\
\hline 20 June 2017 & Sulfoxaflor applied at $450 \mathrm{~g}$ a.i. ha ${ }^{-1}$ or $700 \mathrm{~g}$ a.i. ha ${ }^{-1}$ via drip irrigation 20 days before cotton flowering \\
\hline 30 June 2017 & Sulfoxaflor applied at $450 \mathrm{~g}$ a.i. $\mathrm{ha}^{-1}$ or $700 \mathrm{~g}$ a.i. ha $\mathrm{ha}^{-1}$ via drip irrigation 10 days before cotton flowering \\
\hline 14 July 2017 & Sulfoxaflor applied at $450 \mathrm{~g}$ a.i. $\mathrm{ha}^{-1}$ or $700 \mathrm{~g}$ a.i. ha ${ }^{-1}$ via drip irrigation during cotton flowering \\
\hline
\end{tabular}

\subsection{Sample Collection}

The cultivar flowering lasted about one month (2016: from 3 July to 4 August; 2017: from 10 July to 11 August). The days for sampling pollen and nectar were as follows:

Sulfoxaflor applied 30 days before flowering: In 2016 and 2017, pollen and nectar samples were collected on day $35,40,45$, and 50 after sulfoxaflor application, respectively.

Sulfoxaflor applied 20 days before flowering: In 2016 and 2017, pollen and nectar samples were collected on day 25, 30, 35, and 40 after sulfoxaflor application, respectively.

Sulfoxaflor applied 10 days before flowering: In 2016 and 2017, pollen and nectar samples were collected on day 15, 20,25, and 30 after sulfoxaflor application, respectively.

Sulfoxaflor applied during flowering: In 2016 and 2017, pollen and nectar samples were collected at $2 \mathrm{~h}$ and on day $1,3,5,7,15$, and 20 after sulfoxaflor application, respectively.

Open flowers were picked from plants and placed in bags. The bags were immediately placed in iceboxes and brought to the laboratory for extracting pollen and nectar based on the methods described by Dively and Kamel [28]. All operations were completed on ice. Pollen and nectar samples were frozen immediately and transported to the South China Agricultural University Pesticide Analytical Laboratory and placed in a $-20^{\circ} \mathrm{C}$ freezer until extraction.

\subsection{Sample Preparation}

Two grams of pollen or $1 \mathrm{~mL}$ of nectar samples were placed in a $10 \mathrm{~mL}$ conical centrifuge tube with $3.0 \mathrm{~mL}$ AR-grade acetonitrile and $0.5 \mathrm{~mL}$ water. All tubes were sonicated for $30 \mathrm{~min}$, and $0.5 \mathrm{~g}$ sodium chloride was added, and vortexed mixed for $2 \mathrm{~min}$. All tubes were centrifuged for $5 \mathrm{~min}$ at $6000 \mathrm{rpm}$, and acetonitrile extract (supernatant) was transferred into a $5.0 \mathrm{~mL}$ plastic centrifuge tube containing PSA $(0.1 \mathrm{~g})$ and $\mathrm{C}_{18}(0.1 \mathrm{~g})$ and centrifuged at $6000 \mathrm{rpm}$ for $5 \mathrm{~min}$. The supernatants were evaporated to dryness in a water bath under a stream of $\mathrm{N}^{2}$ at $40{ }^{\circ} \mathrm{C}$. The dried residue was then reconstituted in $2 \mathrm{~mL}$ of acetonitrile and filtered through $0.22 \mu \mathrm{m}$ syringe filter (Nylon) into glass auto-sampler vials for LC-MS analysis.

\subsection{Instrumentation and Condition}

Prepared samples were analyzed by an Agilent UPLC-MS/MS (Infinity ultraperformance liquid chromatograph, Agilent, Beijing, China) with an Eclipse plus $C_{18}$ column $(50 \mathrm{~mm} \times 2.1 \mathrm{~mm}$, i.d. $1.8 \mu \mathrm{m}$ particle size). The mobile phase consisted of $0.01 \%$ formic acid in water (solvent $\mathrm{A}$ ) and acetonitrile (solvent $\mathrm{B}$ ) applied at a flow rate of $0.2 \mathrm{~mL} / \mathrm{min}$ under the following gradient conditions: (1) $0.05 \mathrm{~min}$ (A-B, 95:5, v/v); (2) $2 \min (\mathrm{A}-\mathrm{B}, 5: 95, v / v)$; (3) $5.5 \min (\mathrm{A}-\mathrm{B}, 95: 5, v / v) ;(4) 8 \min (\mathrm{A}-\mathrm{B}, 95: 5, v / v)$. Injection 
volume and column temperature were set at $5 \mu \mathrm{L}$ and $30^{\circ} \mathrm{C}$. The mass spectrometer was operated with ESI source in the positive ionization mode, and sulfoxaflor was detected by multiple reaction monitoring (MRM) with 1 precursor ion and 2 product ions. Optimized MRM parameters of sulfoxaflor were as follows: Qualifying ion pairs were 278.1/174.0 m/z and 278.1/153.9 $\mathrm{m} / \mathrm{z}$, and the quantifying ion pair was 278.1/174.0 m/z; collision energy was $12 \mathrm{~V}$ and $20 \mathrm{~V}$, declustering potential was $100 \mathrm{~V}$. The LOQ $(\mathrm{S} / \mathrm{N}=10)$ and $\operatorname{LOD}(\mathrm{S} / \mathrm{N}=3)$ were $3.87 \mu \mathrm{g} \cdot \mathrm{kg}^{-1}, 1.16 \mu \mathrm{g} \cdot \mathrm{kg}^{-1}$ in pollen and $2.26 \mu \mathrm{g} \cdot \mathrm{kg}^{-1}$, $0.68 \mu \mathrm{g} \cdot \mathrm{kg}^{-1}$ in nectar, respectively. The mean recoveries of sulfoxaflor in pollen and nectar were within 85.67-92.33\% and 83.00-96.18\%, respectively. Additionally, the RSDs ranged within 2.46-3.06\% and $1.17-4.04 \%$, respectively.

\subsection{Risk Assessment}

To understand the risk of sulfoxaflor posed to A. mellifera, the risk assessment was estimated according to the flower hazard quotient $\left(\mathrm{FHQ}_{\mathrm{do}}\right)$ value [29]. The $F H Q_{\mathrm{do}}$ value was calculated from the predicted exposure concentration (PEC) in pollen and nectar multiplied by the maximum contact level (MCL)] and the acute contact $\mathrm{LD}_{50}$ for adult bees. According to the reference, the maximum contact level of honey bees was $1 \mathrm{~g}$ of contaminated flowers per day [29,30]. The contact $\mathrm{LD}_{50} \mathrm{was}$ $0.585 \mu \mathrm{g}$ a.i. bee ${ }^{-1}$ [22]. When the $\mathrm{FHQ}_{\mathrm{do}}$ value was lower than 0.1 , the risk was acceptable, while the value between 0.1 and 1 indicated moderate risk, and the value greater than 1 was considered to be an unacceptable risk.

The above method was suitable for contact exposure, but it may not be appropriate to assess risk by chronic dietary exposure because the bees constantly consume pollen, nectar, and honey. If the residues ingested remained in the body of honey bees, a $\mathrm{LD}_{50}$ could be reached after some time; meanwhile, compounds should have some elimination and metabolism [31], thus the cumulative residue amounts estimated by the above way could represent the worse-case scenario. Therefore, a further assessment of the dietary risk of sulfoxaflor was performed using the fixed-dose approach, where the estimated time to reach the oral $\mathrm{LD}_{50}$ value was compared with the actual lifespan of 3 types of honeybee (worker larvae, nurses, and foragers) [30]. The oral $\mathrm{LD}_{50}$ was $0.187 \mu \mathrm{g}$ a.i. bee ${ }^{-1}$ [22]. When the time was shorter than the lifespan, it represented a serious risk [30]. The time reach to oral $\mathrm{LD}_{50}$ was calculated as follow:

$$
\mathrm{T} 50 \text { (days })=\frac{(\text { oral LD50 }(\mu \mathrm{g} / \mathrm{bee}))}{\text { Daily dose }(\mu \mathrm{g})}
$$

The consumption rates of three types of A. mellifera. was referred to as the references [30,32]. Since nectar was to be dehydrated to concentrate the sugar to honey, we estimated daily consumption rates on the basis of total sugar intake (mg). According to the reference [33,34], nectar of cotton flowers contains between $17.9 \%-36.5 \%$ of sugar and honey contains, on average $80 \%$ of sugar. In the calculation process, we firstly converted honey to sugar and then sugar to nectar.

\subsection{Statistical Analyses}

All data were subjected to analysis of variance (ANOVA) using SPSS software (version 15.0; SPSS Inc., Chicago, IL, USA). When significance occurred, means were separated by Tukey's HSD test $(p<0.05)$. The data of sulfoxaflor concentrations were presented as the mean \pm standard errors with 3 replications.

\section{Results}

\subsection{Sulfoxaflor Concentration in Pollen and Nectar}

Sulfoxaflor concentrations in pollen and nectar of cotton plants produced in 2016 are presented in Table 2. Results showed that the levels of sulfoxaflor residue differed in pollen and nectar and also varied by application times and doses. Sulfoxaflor was not detectable in pollen and nectar when it 
was applied 30 days before flowering. When sulfoxaflor was applied 20 days before flowering at $700 \mathrm{~g}$ a.i. $\mathrm{ha}^{-1}$, it was detected in pollen only $\left(<9 \mu \mathrm{g} \cdot \mathrm{kg}^{-1}\right) 25$ days after the application. When it was applied 10 days before flowering, sulfoxaflor concentrations up to $14.2 \mu \mathrm{g} \cdot \mathrm{kg}^{-1}$ were detected in pollen of plants after 15 and 20 days of application. Application of the low dose during flowering, sulfoxaflor residues was detected in pollen only ranging from 7.7 to $17 \mu \mathrm{g} \cdot \mathrm{kg}^{-1}$. Application of the high dose during flowering, sulfoxaflor residue varied from 11.7 to $39.2 \mu \mathrm{g} \cdot \mathrm{kg}^{-1}$ in pollen and 6.6 to $13.8 \mu \mathrm{g} \cdot \mathrm{kg}^{-1}$ in nectar depending on the days of sampling. Sulfoxaflor concentrations in pollen of plants treated with $700 \mathrm{~g}$ a.i. ha ${ }^{-1}$ during the flowering stage from day 5 to day 7 were significantly higher than the other treatments $(F=11.40, d f=13,28, p<0.001)$, but there were no significant differences within the other treatments.

Table 2. Concentration of sulfoxaflor in pollen and nectar of cotton plants applied with two doses of sulfoxaflor through drip irrigation at different times in 2016.

\begin{tabular}{|c|c|c|c|c|c|}
\hline \multirow{3}{*}{$\begin{array}{l}\text { Application } \\
\text { Time }\end{array}$} & \multirow{3}{*}{$\begin{array}{l}\text { Days after } \\
\text { Treatment }\end{array}$} & \multicolumn{4}{|c|}{ Concentration $\left(\mu \mathrm{g} \cdot \mathrm{kg}^{-1}\right) \pm \mathrm{SE}$} \\
\hline & & \multicolumn{2}{|c|}{$450 \mathrm{~g}$ a.i. ha $\mathrm{h}^{-1}$} & \multicolumn{2}{|c|}{$700 \mathrm{~g}$ a.i. ha $\mathrm{h}^{-1}$} \\
\hline & & Pollen & Nectar & Pollen & Nectar \\
\hline \multirow{4}{*}{$\begin{array}{l}30 \text { days before } \\
\text { flowering }\end{array}$} & $35 d$ & $\mathrm{BDL}^{\mathrm{z}}$ & BDL $^{y}$ & BDL & BDL \\
\hline & $40 \mathrm{~d}$ & BDL & BDL & BDL & BDL \\
\hline & $45 \mathrm{~d}$ & BDL & BDL & $\mathrm{BDL}$ & $\mathrm{BDL}$ \\
\hline & $50 \mathrm{~d}$ & BDL & BDL & BDL & BDL \\
\hline \multirow{4}{*}{$\begin{array}{l}20 \text { days before } \\
\text { flowering }\end{array}$} & $25 \mathrm{~d}$ & BDL & BDL & $8.9 \pm 1.4 c^{x}$ & BDL \\
\hline & $30 d$ & BDL & BDL & BDL & BDL \\
\hline & $35 d$ & BDL & BDL & BDL & BDL \\
\hline & $40 \mathrm{~d}$ & BDL & BDL & BDL & BDL \\
\hline \multirow{4}{*}{$\begin{array}{l}10 \text { days before } \\
\text { flowering }\end{array}$} & $15 d$ & $5.7 \pm 1.5 c$ & BDL & $14.2 \pm 1.4 \mathrm{c}$ & BDL \\
\hline & $20 d$ & BDL & $\mathrm{BDL}$ & $8.5 \pm 1.6 c$ & $\mathrm{BDL}$ \\
\hline & $25 d$ & BDL & BDL & BDL & BDL \\
\hline & $30 \mathrm{~d}$ & BDL & BDL & BDL & BDL \\
\hline \multirow{7}{*}{$\begin{array}{l}\text { During } \\
\text { flowering }\end{array}$} & $0.08 \mathrm{~d}$ & BDL & BDL & BDL & $\mathrm{BDL}$ \\
\hline & $1 d$ & BDL & $\mathrm{BDL}$ & $\mathrm{BDL}$ & $\mathrm{BDL}$ \\
\hline & $3 d$ & BDL & BDL & $18.0 \pm 1.3 b c$ & BDL \\
\hline & $5 d$ & $17.0 \pm 3.5 c$ & BDL & $39.2 \pm 4.0 \mathrm{a}$ & $13.8 \pm 2.6 c$ \\
\hline & $7 d$ & $15.3 \pm 2.6 c$ & BDL & $31.7 \pm 4.8 \mathrm{ab}$ & $6.6 \pm 1.3 c$ \\
\hline & $15 \mathrm{~d}$ & $7.7 \pm 2.3 c$ & BDL & $16.9 \pm 4.3 c$ & BDL \\
\hline & $20 \mathrm{~d}$ & BDL & $\mathrm{BDL}$ & $11.7 \pm 2.9 \mathrm{c}$ & BDL \\
\hline
\end{tabular}

z BDL (below detectable level) $<1.16 \mu \mathrm{g} \cdot \mathrm{kg}^{-1}$. ${ }^{\mathrm{y}}$ BDL (below detectable level) $<0.68 \mu \mathrm{g} \cdot \mathrm{kg}^{-1} \cdot{ }^{\mathrm{x}}$ Means followed by different letters in the same column indicate significant differences in sulfoxaflor residue levels based on Tukey's HSD test $(p<0.05)$.

Residue concentrations of sulfoxaflor in pollen and nectar of plants treated with two doses of sulfoxaflor at different times in 2017 were similar to those of 2016, which is presented in Table 3. Sulfoxaflor concentrations were $\leq 13.5 \mu \mathrm{g} \cdot \mathrm{kg}^{-1}$ in pollen and below the detection limit in nectar when sulfoxaflor was applied before flowering. During flowering, drip application of two different doses of sulfoxaflor resulted in $8.9-34.6 \mu \mathrm{g} \cdot \mathrm{kg}^{-1}$ in pollen and $7.6-10.8 \mu \mathrm{g} \cdot \mathrm{kg}^{-1}$ in nectar. By comparison, sulfoxaflor concentrations in pollen of plants after 5 and 7 days of treatment with the high dose during the flowering period were significantly higher than the other treatments $(F=16.71, d f=12,26, p<0.001)$; there were no significant differences within the other treatments. 
Table 3. Concentration of sulfoxaflor in pollen and nectar of cotton plants applied with two doses of sulfoxaflor through drip irrigation at different times in 2017.

\begin{tabular}{|c|c|c|c|c|c|}
\hline \multirow{3}{*}{$\begin{array}{l}\text { Application } \\
\text { Time }\end{array}$} & \multirow{3}{*}{$\begin{array}{l}\text { Days after } \\
\text { Treatment }\end{array}$} & \multicolumn{4}{|c|}{ Concentration $\left(\mu \mathrm{g} \cdot \mathrm{kg}^{-1}\right) \pm \mathrm{SE}$} \\
\hline & & \multicolumn{2}{|c|}{$450 \mathrm{~g}$ a.i. ha ${ }^{-1}$} & \multicolumn{2}{|c|}{$700 \mathrm{~g}$ a.i. ha ${ }^{-1}$} \\
\hline & & Pollen & Nectar & Pollen & Nectar \\
\hline \multirow{4}{*}{$\begin{array}{l}30 \text { days before } \\
\text { flowering }\end{array}$} & $35 \mathrm{~d}$ & $\mathrm{BDL}^{\mathrm{z}}$ & $\mathrm{BDL}^{\mathrm{y}}$ & BDL & BDL \\
\hline & $40 \mathrm{~d}$ & BDL & BDL & BDL & BDL \\
\hline & $45 \mathrm{~d}$ & BDL & BDL & BDL & BDL \\
\hline & $50 \mathrm{~d}$ & $\mathrm{BDL}$ & $\mathrm{BDL}$ & $\mathrm{BDL}$ & $\mathrm{BDL}$ \\
\hline \multirow{4}{*}{$\begin{array}{l}20 \text { days before } \\
\text { flowering }\end{array}$} & $25 \mathrm{~d}$ & BDL & BDL & $6.6 \pm 1.1 \mathrm{de}^{\mathrm{x}}$ & BDL \\
\hline & $30 \mathrm{~d}$ & BDL & BDL & BDL & BDL \\
\hline & $35 \mathrm{~d}$ & BDL & BDL & BDL & BDL \\
\hline & $40 \mathrm{~d}$ & BDL & BDL & BDL & BDL \\
\hline \multirow{4}{*}{$\begin{array}{l}10 \text { days before } \\
\text { flowering }\end{array}$} & $15 \mathrm{~d}$ & $7.0 \pm 1.8 \mathrm{de}$ & BDL & $13.5 \pm 1.9 \mathrm{bcde}$ & BDL \\
\hline & $20 \mathrm{~d}$ & BDL & BDL & $5.8 \pm 1.6 \mathrm{e}$ & BDL \\
\hline & $25 \mathrm{~d}$ & BDL & BDL & BDL & $\mathrm{BDL}$ \\
\hline & $30 \mathrm{~d}$ & $\mathrm{BDL}$ & $\mathrm{BDL}$ & $\mathrm{BDL}$ & $\mathrm{BDL}$ \\
\hline \multirow{7}{*}{$\begin{array}{l}\text { During } \\
\text { flowering }\end{array}$} & $0.08 \mathrm{~d}$ & BDL & BDL & BDL & BDL \\
\hline & $1 d$ & BDL & BDL & $\mathrm{BDL}$ & BDL \\
\hline & $3 \mathrm{~d}$ & $\mathrm{BDL}$ & BDL & $16.7 \pm 1.3 \mathrm{bcd}$ & BDL \\
\hline & $5 \mathrm{~d}$ & $15.9 \pm 1.2 \mathrm{bcde}$ & BDL & $34.6 \pm 4.9 \mathrm{a}$ & $10.8 \pm 1.1 \mathrm{cde}$ \\
\hline & $7 \mathrm{~d}$ & $10.9 \pm 1.4$ cde & BDL & $23.3 \pm 1.7 \mathrm{~b}$ & $7.6 \pm 1.9 \mathrm{cde}$ \\
\hline & $15 \mathrm{~d}$ & $\mathrm{BDL}$ & $\mathrm{BDL}$ & $17.5 \pm 1.4 \mathrm{bc}$ & BDL \\
\hline & $20 \mathrm{~d}$ & BDL & BDL & $8.9 \pm 1.5 \mathrm{cde}$ & BDL \\
\hline
\end{tabular}

${ }^{\mathrm{z}}$ BDL (below detectable level) $<1.16 \mu \mathrm{g} \cdot \mathrm{kg}^{-1}$. ${ }^{\mathrm{y}}$ BDL (below detectable level) $<0.68 \mu \mathrm{g} \cdot \mathrm{kg}^{-1}$. ${ }^{\mathrm{x}}$ Means followed by different letters in the same column indicate significant differences in sulfoxaflor residue levels based on Tukey's HSD test $(p<0.05)$.

\subsection{Potential Risk Assessment to A. Mellifera}

The contact exposure of sulfoxaflor to honey bees in 2016 and 2017 was estimated by the flower hazard quotient $\left(\mathrm{FHQ}_{\mathrm{do}}\right)$ [29]. The results showed that $F H Q_{\mathrm{do}}$ values were lower than 0.1 for the two doses of sulfoxaflor applied either before or during flowering (Table 4; Table 5). The results showed that drip application of the two different doses of sulfoxaflor before or during flowering had little risks by contact exposure to honey bees.

Table 4. Contact exposure risk levels of sulfoxaflor applied through drip irrigation at different times to A. mellifera in 2016.

\begin{tabular}{|c|c|c|c|}
\hline \multirow{2}{*}{ Application Time } & \multirow{2}{*}{ Days after Treatment } & \multicolumn{2}{|c|}{ Contact Flower Hazard Quotient $\left(F Q_{\mathrm{do}}\right)$} \\
\hline & & 700 g a.i. ha ${ }^{-1}$ & $450 \mathrm{~g}$ a.i. ha ${ }^{-1}$ \\
\hline \multirow{4}{*}{30 days before flowering } & $35 d$ & - & - \\
\hline & $40 \mathrm{~d}$ & - & - \\
\hline & $45 d$ & - & - \\
\hline & $50 \mathrm{~d}$ & - & - \\
\hline \multirow{4}{*}{20 days before flowering } & $25 d$ & - & 0.02 \\
\hline & $30 \mathrm{~d}$ & - & - \\
\hline & $35 d$ & - & - \\
\hline & $40 \mathrm{~d}$ & - & - \\
\hline \multirow{4}{*}{10 days before flowering } & $15 d$ & 0.01 & 0.02 \\
\hline & $20 \mathrm{~d}$ & - & 0.01 \\
\hline & $25 d$ & - & - \\
\hline & $30 d$ & - & - \\
\hline \multirow{7}{*}{ During flowering } & $0.08 \mathrm{~d}$ & - & - \\
\hline & $1 d$ & - & - \\
\hline & $3 d$ & - & 0.03 \\
\hline & $5 \mathrm{~d}$ & 0.03 & 0.09 \\
\hline & $7 d$ & 0.03 & 0.07 \\
\hline & $15 d$ & 0.01 & 0.03 \\
\hline & $20 \mathrm{~d}$ & - & 0.02 \\
\hline
\end{tabular}


Table 5. Contact exposure risk levels of sulfoxaflor applied through drip irrigation at different times to A. mellifera in 2017.

\begin{tabular}{|c|c|c|c|}
\hline \multirow{2}{*}{ Application Time } & \multirow{2}{*}{$\begin{array}{l}\text { Days after } \\
\text { Treatment }\end{array}$} & \multicolumn{2}{|c|}{ Contact Flower Hazard Quotient $\left(\mathrm{FHQ}_{\mathrm{do}}\right)$} \\
\hline & & 450 g a.i. ha ${ }^{-1}$ & $700 \mathrm{~g}$ a.i. ha $\mathrm{h}^{-1}$ \\
\hline \multirow{4}{*}{30 days before flowering } & $35 \mathrm{~d}$ & - & - \\
\hline & $40 \mathrm{~d}$ & - & - \\
\hline & $45 \mathrm{~d}$ & - & - \\
\hline & $50 \mathrm{~d}$ & - & - \\
\hline \multirow{4}{*}{20 days before flowering } & $25 \mathrm{~d}$ & - & 0.01 \\
\hline & $30 \mathrm{~d}$ & - & - \\
\hline & $35 \mathrm{~d}$ & - & - \\
\hline & $40 \mathrm{~d}$ & - & - \\
\hline \multirow{4}{*}{10 days before flowering } & $15 \mathrm{~d}$ & 0.01 & 0.02 \\
\hline & $20 \mathrm{~d}$ & - & 0.01 \\
\hline & $25 \mathrm{~d}$ & - & - \\
\hline & $30 \mathrm{~d}$ & - & - \\
\hline \multirow{7}{*}{ During flowering } & $0.08 \mathrm{~d}$ & - & - \\
\hline & $1 d$ & - & - \\
\hline & $3 d$ & - & 0.03 \\
\hline & $5 \mathrm{~d}$ & 0.03 & 0.08 \\
\hline & $7 \mathrm{~d}$ & 0.02 & 0.05 \\
\hline & $15 \mathrm{~d}$ & - & 0.03 \\
\hline & $20 \mathrm{~d}$ & - & 0.02 \\
\hline
\end{tabular}

The dietary exposure of sulfoxaflor was estimated by the $\mathrm{T}_{50}$ for representative three honey bee types. The results showed that all $\mathrm{T}_{50}$ values were longer than those lifespan of three different types of bees (Tables 6 and 7) [30]. The results indicated that drip application of sulfoxaflor at the mentioned two rates should have no dietary exposure risks to three different types of honey bees.

Table 6. Dietary exposure risk levels of sulfoxaflor to three different types of A. mellifera in 2016.

\begin{tabular}{|c|c|c|c|c|c|c|c|}
\hline \multirow{3}{*}{ Application Time } & \multirow{3}{*}{$\begin{array}{l}\text { Days after } \\
\text { Treatment }\end{array}$} & \multicolumn{6}{|c|}{$\mathrm{T}_{50}{ }^{1}$ (days) } \\
\hline & & \multicolumn{3}{|c|}{$450 \mathrm{~g}$ a.i. ha $\mathrm{h}^{-1}$} & \multicolumn{3}{|c|}{$700 \mathrm{~g}$ a.i. ha ${ }^{-1}$} \\
\hline & & Worker Larvae & Nurses & Forager & Worker Larvae & Nurses & Forager \\
\hline 20 days before flowering & $25 \mathrm{~d}$ & - & - & - & $19,101.1$ & 3232.5 & - \\
\hline \multirow{2}{*}{10 days before flowering } & $15 \mathrm{~d}$ & $29,824.6$ & 5047.2 & - & $11,971.8$ & 2026.0 & - \\
\hline & $20 \mathrm{~d}$ & - & - & - & $20,000.0$ & 3384.6 & - \\
\hline \multirow[t]{5}{*}{ During flowering } & $3 d$ & - & - & - & 9444.4 & 1598.3 & - \\
\hline & $5 \mathrm{~d}$ & 10,000 & 1692.3 & - & $102.4-204.0$ & 733.9 & $37.8-475.5$ \\
\hline & $7 \mathrm{~d}$ & $11,111.1$ & 1880.3 & - & $210.7-413.1$ & 907.6 & $79.1-994.2$ \\
\hline & $15 d$ & $22,077.9$ & 3736.3 & - & $10,059.2$ & 1702.3 & - \\
\hline & $20 \mathrm{~d}$ & - & - & - & $14,529.9$ & 2458.9 & - \\
\hline
\end{tabular}

Table 7. Dietary exposure risk levels of sulfoxaflor to three different types of A. mellifera in 2017.

\begin{tabular}{|c|c|c|c|c|c|c|c|}
\hline \multirow{3}{*}{ Application Time } & \multirow{3}{*}{$\begin{array}{l}\text { Days after } \\
\text { Treatment }\end{array}$} & \multicolumn{6}{|c|}{$\mathrm{T}_{50}{ }^{1}$ (days) } \\
\hline & & \multicolumn{3}{|c|}{450 g a.i. ha $a^{-1}$} & \multicolumn{3}{|c|}{$700 \mathrm{~g}$ a.i. ha $\mathrm{h}^{-1}$} \\
\hline & & Worker Larvae & Nurses & Forager & Worker Larvae & Nurses & Forager \\
\hline 20 days before flowering & $25 \mathrm{~d}$ & - & - & - & $25,757.6$ & 4359.0 & - \\
\hline \multirow{2}{*}{10 days before flowering } & $15 d$ & $24,285.7$ & 4109.9 & - & $12,592.6$ & 2131.1 & - \\
\hline & $20 \mathrm{~d}$ & - & - & - & $29,310.3$ & 4960.2 & - \\
\hline \multirow[t]{5}{*}{ During flowering } & $3 d$ & - & - & - & $10,179.6$ & 1722.7 & - \\
\hline & $5 d$ & $10,691.82$ & 1809.4 & - & $130.5-259.1$ & 831.5 & $48.3-607.5$ \\
\hline & $7 \mathrm{~d}$ & $15,596.33$ & 2639.4 & - & $185.6-369.1$ & 1234.7 & $68.7-863.3$ \\
\hline & $15 d$ & - & - & - & 9714.3 & 1644.0 & - \\
\hline & $20 \mathrm{~d}$ & - & - & - & $19,101.1$ & 3232.5 & - \\
\hline
\end{tabular}




\section{Discussion}

Cotton production plays an important role in Xinjiang's economic growth and development. Due to the monoculture, cotton aphid has become a notorious problem. Foliar application of chemical pesticides is a common way of controlling aphid. However, foliar application of pesticides has negative effects on the environment and beneficial organisms, particularly in bees [15,16]. Bees are essential pollinators in natural ecosystems and agricultural crops $[35,36]$. The risk of pesticides to bees has become a worldwide concern and attracted increasing research on bee safety [36,37]. As a part of the efforts, this study investigated the residue levels of sulfoxaflor applied via drip irrigation in cotton pollen and nectar at different times and its potential risk to A. mellifera. Our results showed that the closer the application time to the flowering period was, the higher the concentration of sulfoxaflor in pollen and nectar of cotton could be. Because sulfoxaflor is a pesticide that can be easily degraded in cotton plants [38], the longer the time after application is, the lower the concentration of sulfoxaflor in pollen and nectar will be. Compared to the pesticide residues reported by Siviter et al. [23], concentrations of sulfoxaflor in pollen and nectar were lower in our study. This difference might result from different application methods. Because sulfoxaflor applied via foliar spray was directly on the surface of plants, which could result in flowers with a higher concentration of sulfoxaflor. On the other hand, sulfoxaflor applied through drip irrigation was not on the surface of plants, and honey bees could have no direct contact with the pesticide. Our results manifested that drip irrigation reduced the potential risk of sulfoxaflor to honey bees. Alarcón (2005) also reported that drip application of thiamethoxam reduced the side effect on bumble-bees [39]. By comparison, the concentrations of sulfoxaflor in pollen were higher than those in nectar. This trend concurred with references [23,28]. Additionally, there was no significant differences between 2016 and 2017 in sulfoxaflor concentrations in pollen and nectar of cotton. This could be due in part to the similar weather conditions where the average daily air temperature, mean monthly precipitation, and mean daily sunshine duration of the field sites were $24.2{ }^{\circ} \mathrm{C}, 81.3 \mathrm{~mm}$, and $12.2 \mathrm{~h}$ in 2016 and $25.3^{\circ} \mathrm{C}, 46.5 \mathrm{~mm}$, and $13.4 \mathrm{~h}$ in 2017 .

Bees can be exposed to insecticide in two ways in open fields: (1) Bees are directly exposed to drift droplets from foliar spray, or dust from seed drilling at planting, or inhalation of volatile pesticides during or after application and (2) bees are exposed to residues in pollen, nectar, honey, and water [40-43]. In this study, our risk assessment dealt only with residues in pollen and nectar. Because bees were mainly exposed to sulfoxaflor by pollen and nectar when sulfoxaflor was applied via drip irrigation [44]. Firstly, we assessed the contact exposure of sulfoxaflor on honey bees by the flower hazard quotient $\left(\mathrm{FHQ}_{\mathrm{do}}\right)[29]$, and the results showed that all $\mathrm{FHQ}_{\mathrm{do}}$ values were lower than 0.1, indicating that sulfoxaflor residues in pollen and nectar were safe to honey bees ( Table 4; Table 5) [29]. Honey bees generally have different types, such as worker larvae, nurses, and forager. Different types of honey bees have different habits and different sensitivities to residues of pesticides [30]. Therefore, the dietary exposure of sulfoxaflor to three different types of honey bees (worker larvae, nurses, and foragers) was estimated by the $T_{50}$, and the results showed that all $T_{50}$ values were longer than the lifespan of three different types of honey bees [30], suggesting that residues of sulfoxaflor in pollen and nectar were safe to three different types of bees (Table 6; Table 7). In general, worker larvae and foragers of honey bees do not eat nectar, they eat honey. Nectar is dehydrated to concentrate sugar to honey. According to reference [33], honey contains an average of $80 \%$ of sugar. Meanwhile, the nectar of cotton flowers contains $17.9 \%-36.5 \%$ of sugar [34]. Therefore, the concentration of sulfoxaflor in nectar would be concentrated and the concentration of sulfoxaflor in honey was to be higher in honey. Our calculation showed that the concentrations of sulfoxaflor in honey could be within 46.1-96.4 $\mu \mathrm{g} \cdot \mathrm{kg}^{-1}$. According to the above results of risk assessment, the drip application of two different doses of sulfoxaflor before or during flowering appeared to have little negative risk to honeybees. Thus, drip irrigation could be an environmentally friend way of applying systemic insecticides for controlling aphid while safeguarding honeybees. 


\section{Conclusions}

This is the first systematic evaluation of the safety of sulfoxaflor applied through drip irrigation at different times before flowering and during flowering to A. mellifera. Even though the drip application of high dose of sulfoxaflor during flowering resulted in higher residues in pollen and nectar, risk assessments by contact exposure and dietary exposure showed that drip application of sulfoxaflor should have little negative effects on honeybees. Our results indicate that the drip application of sulfoxaflor could represent a sustainable way of controlling aphid while protecting beneficial organisms during cotton production.

Author Contributions: Conceptualization, Z.Z.; Formal analysis, Y.T.; Investigation, H.J.; Methodology, J.C.; Project administration, Y.T. and H.X.; Supervision, Z.Z.; Writing—original draft, H.J.; Writing—review \& editing, H.J., J.C. and C.Z. All authors have read and agreed to the published version of the manuscript.

Funding: This work was supported by the National Key R\&D Program of China (2017YFD0200307) and the Major projects of China Spark Program (2015GA780005).

Conflicts of Interest: The authors declare no competing financial interest.

\section{References}

1. Kuhar, T.P.; Doughty, H.; Hitchner, E.; Cassell, M. Evaluation of insecticide treatments for the control of lepidopteran pests in bell peppers in Virginia, 2007. Arthropod Manag. Tests 2008, 33, E7. [CrossRef]

2. Kuhar, T.P.; Walgenbach, J.F.; Doughty, H.B. Control of Helicoverpa zea in tomatoes with chlorantraniliprole applied through drip chemigation. Plant Health Progress 2010. [CrossRef]

3. Ghidiu, G.; Kuhar, T.P.; Palumbo, J.C.; Schuster, D. Drip chemigation of insecticides as a pest management tool in vegetable production. J. Integr. Pest Manag. 2012, 3, E1-E5. [CrossRef]

4. Arrington, A.E.; Kennedy, G.G.; Abney, M.R. Applying insecticides through drip irrigation to reduce wireworm (Coleoptera: Elateridae) feeding damage in sweet potato. Pest Manag. Sci. 2015, 72, 1133-1140. [CrossRef]

5. Ristaino, J.B.; Johnston, S.A. Ecologically based approaches to management of Phytopthera blight on bell peppers. Plant Dis. 1999, 83, 1080-1089. [CrossRef]

6. Palumbo, J.C. Systemic efficacy of Coragen applied through drip irrigation on romaine lettuce, fall 2007. Arthropod Manag. Tests 2008, 33, E24. [CrossRef]

7. Ghidiu, G.M. Control of insect pests of eggplant with insecticides applied through a drip irrigation system under black plastic. Veg. Entomol. Res. Results Rutgers Univ. Coop. Ext. Bull. 2009, 104, 8-11.

8. He, J.T.; Zhou, L.; Yao, Q.; Liu, B.; Xu, H.; Huang, J. Greenhouse and field-based studies on the distribution of dimethoate in cotton and its effect on Tetranychus urticae by drip irrigation. Pest Manag. Sci. 2018, 74, 225-233. [CrossRef]

9. Jiang, H.; Wu, H.X.; Chen, J.J.; Tian, T.Y.; Zhang, Z.X.; Xu, H.H. Sulfoxaflor Applied via Drip Irrigation Effectively Controls Cotton Aphid (Aphis gossypii Glover). Insects 2019, 10, 345. [CrossRef]

10. Jiang, H.; Tiana, Y.Q.; Yan, W.J.; Chen, J.J.; Zhang, Z.X.; Xu, H.H. Drip chemigation of flonicamid effectively controls cotton aphid (Aphis gossypii) and is benign to lady beetle (Coccinella septempunctata) and lacewing larva (Chrysoperla sinica). Crop Prot. 2020, 129, 105039. [CrossRef]

11. Dai, J.L.; Dong, H.Z. Intensive cotton farming technologies in China: Achievements, challenges and countermeasures. Field Crop Res. 2014, 99, 99-110. [CrossRef]

12. Li, J.; Zhao, W.; Yin, J.; Zhang, H.; Li, Y.; Wen, J. The effects of drip irrigation system uniformity on soil water and nitrogen distributions. Trans. Asabe 2012, 55, 415-427. [CrossRef]

13. Zhao, B.; Wang, Z.; Li, W. Effects of winter drip irrigation mode and quota on water and salt distribution in cotton field soil and cotton growth next year in northern Xinjiang. Trans. Chin. Soc. Agric. Eng. 2016, 32, 139-148.

14. Du, M. The Chinese Cotton Industry in the Context of Marketization and Globalization; China Agriculture Press: Beijing, China, 2012; pp. 27-38. (In Chinese)

15. Klein, A.M.; Vaissière, B.E.; Cane, J.H.; Steffan-Dewenter, I.; Cunningham, S.A.; Kremen, C.; Tscharntke, T. Importance of pollinators in changing landscapes for world crops. Proc. R. Soc. B 2007, 274, 303-313. [CrossRef] 
16. Velthuis, H.H.W.; Van Doorn, A. A century of advances in bumblebee domestication and the economic and environmental aspects of its commercialization for pollination. Apidologie 2006, 37, 421-451. [CrossRef]

17. Zhu, Y.M.; Loso, M.R.; Watson, G.; Sparks, T.C.; Rogers, R.B.; Huang, X.; Gerwick, B.C.; Babcock, J.M.; Kelley, D.; Hegde, V.B.; et al. Discovery and characterization of sulfoxaflor, a novel insecticide targeting sap-feeding pests. J. Agric. Food Chem. 2011, 59, 2950-2957. [CrossRef]

18. Sparks, T.C.; Watson, G.B.; Loso, M.R.; Geng, C.; Babcock, J.M.; Thomas, J.D. Sulfoxaflor and the sulfoximine insecticides: Chemistry, mode of action and basis for efficacy on resistant insects. Pestic. Biochem. Physiol. 2013, 107, 1-7. [CrossRef]

19. Cutler, P.; Slater, R.; Edmunds, A.J.; Maienfisch, P.; Hall, R.G.; Earley, F.G.; Pitterna, T.; Pal, S.; Paul, V.L.; Goodchild, J.; et al. Investigating the mode of action of sulfoxaflor: A fourth-generation neonicotinoid. Pest Manag. Sci. 2013, 69, 607-619. [CrossRef]

20. Babcock, J.M.; Gerwick, C.B.; Huang, J.X.; Loso, M.R.; Nakamura, G.; Nolting, S.P.; Rogers, R.B.; Sparks, T.C.; Thomas, J.; Watson, G.B.; et al. Biological characterization of sulfoxaflor, a novel insecticide. Pest Manag. Sci. 2011, 67, 328-334. [CrossRef]

21. Zhou, H.; Shao, J.N.; Zhai, Y.F.; Wu, G.A.; Chen, H.; Men, X.Y.; Yu, Y.; Zheng, L. Toxicity and risk assessment of sulfoxaflor, spinetoram and their mixture to Bombus terrestris (Hymenoptera: Apidae). Acta Entomol. Sin. 2017, 60, 809-816.

22. Cang, T.; Wang, Y.H.; Wu, C.X.; Wang, X.Y.; Xu, M.F.; Chen, L.P.; Wang, Q.; Cai, L.M.; Zhao, X.P. Acute toxicity and risk assessment of neonicotinoid insecticides to honeybees (Apis mellifera L.). Asian J. Ecotoxicol. 2017, 12, 285-292.

23. Siviter, H.; Brown, M.J.F.; Leadbeater, E. Sulfoxaflor exposure reduces bumblebee reproductive success. Nature 2018, 561, 108-111. [CrossRef]

24. EPA (United States Environmental Protection Agency). Technical Overview of Ecological Risk Assessment-Analysis Phase: Ecological Effects Characterization. Available online: https://www.epa.gov/ pesticide-science-and-assessing-pesticide-risks/technical-overview-ecological-risk-assessment-0 (accessed on 29 December 2019).

25. Milner, A.M.; Boyd, I.L. Toward pesticidovigilance. Science 2017, 357, 1232-1234. [CrossRef]

26. Bryden, J.; Gill, R.J.; Mitton, R.A.A.; Raine, N.E.; Jansen, V.A.A. Chronic sublethal stress causes bee colony failure. Ecol. Lett. 2013, 16, 1463-1469. [CrossRef]

27. Baron, G.L.; Jansen, V.A.A.; Brown, M.J.F.; Raine, N.E. Pesticide reduces bumblebee colony initiation and increases probability of population extinction. Nat. Ecol. Evol. 2017, 1, 1308-1316. [CrossRef] [PubMed]

28. Dively, G.P.; Kamel, A. Insecticide Residues in Pollen and Nectar of a Cucurbit Crop and Their Potential Exposure to Pollinators. J. Agric. Food Chem. 2012, 60, 4449-4456. [CrossRef] [PubMed]

29. Tong, Z.; Duan, J.S.; Wu, Y.C.; Liu, Q.Q.; He, Q.B.; Shi, Y.H.; Yu, L.S.; Cao, H.Q. Evaluation of Highly Detectable Pesticides Sprayed in Brassica napus L.: Degradation Behavior and Risk Assessment for Honeybees. Molecules 2018, 23, 2482. [CrossRef] [PubMed]

30. Sanchez-Bayo, F.; Goka, K. Pesticide Residues and Bees-A Risk Assessment. PLoS ONE 2014, 9, e94482. [CrossRef]

31. Suchail, S.; Debrauwer, L.; Belzunces, L.P. Metabolism of imidacloprid in Apis mellifera. Pest Manag. Sci. 2004, 60, 291-296. [CrossRef]

32. Rortais, A.; Arnold, G.; Halm, M.P.; Touffet-Briens, F. Modes of honeybees exposure to systemic insecticides: Estimated amounts of contaminated pollen and nectar consumed by different categories of bees. Apidologie 2005, 36, 71-83. [CrossRef]

33. Crane, E. Honey: A Comprehensive Survey; Heinemann: London, UK, 1975.

34. Zhu, X.Y.; Zhu, S.Y. Advances in research on nectariless characters of cotton. Chin. Countrys. Well-off Technol. 2006, 10, 20-22.

35. Gallai, N.; Salles, J.M.; Settele, J.; Vaissière, B.E. Economic valuation of the vulnerability of world agriculture confronted with pollinator decline. Ecol. Econ. 2009, 68, 810-821. [CrossRef]

36. Blacquière, T.; Smagghe, G.; Gestel, C.A.M.V.; Mommaerts, V. Neonicotinoids in bees: A review on concentrations, side-effects and risk assessment. Ecotoxicology 2012, 21, 973-992. [CrossRef] [PubMed]

37. Decourtye, A.; Devillers, J.; Cluzeau, S.; Charreton, M.; Pham-Delègue, M. Effects of imidacloprid and deltamethrin on associative learning in honeybees under semi-field and laboratory conditions. Ecotox. Environ. Saf. 2004, 57, 410-419. [CrossRef] 
38. Qin, X.; Xu, Y.M.; Sun, Y.; Zhao, L.J.; Liu, Y.T. Residue Determination and Degradation of Sulfoxaflor in Cotton and Soil. J. Agric. Resour. Environ. 2014, 31, 381-387.

39. Alarcón, A.L.; Cánovas, M.; Senn, R.; Correia, R. The safety of thiamethoxam to pollinating bumble bees (Bombus terrestris L.) when applied to tomato plants through drip irrigation. Commun. Agric. Appl. Biol. Sci. 2005, 70, 569-579.

40. Thompson, H.M. Assessing the exposure and toxicity of pesticides to bumblebees (Bombus sp.). Apidologie 2001, 32, 305-321. [CrossRef]

41. Goulson, D. An overview of the environmental risks posed by neonicotinoid insecticides. J. Appl. Ecol. 2013, 50, 977-987. [CrossRef]

42. Stoner, K.A.; Eitzer, B.D. Movement of soil-applied imidacloprid and thiamethoxam into nectar and pollen of squash (Cucurbita pepo). PLoS ONE 2012, 7, e39114. [CrossRef]

43. Kovac, H.; Stabentheiner, A.; Schmaranzer, S. Thermoregulation of water foraging honeybees-Balancing of endothermic activity with radiative heat gain and functional requirements. J. Insect Physiol. 2010, 56, 1834-1845. [CrossRef]

44. EPA (United States Environmental Protection Agency). White Paper in Support of the Proposed Risk Assessment Process for Bees. Available online: http://cues.cfans.umn.edu/old/pollinators/pdf-EPA/EAPSAP-whitepaper.pdf (accessed on 29 December 2019).

(C) 2020 by the authors. Licensee MDPI, Basel, Switzerland. This article is an open access article distributed under the terms and conditions of the Creative Commons Attribution (CC BY) license (http://creativecommons.org/licenses/by/4.0/). 